\title{
Impact of elevated nitrate on sulfate-reducing bacteria: a comparative Study of Desulfovibrio vulgaris
}

\author{
Qiang $\mathrm{He}^{1,2}$, Zhili He ${ }^{3,4}$, Dominique C Joyner ${ }^{4,5}$, Marcin Joachimiak ${ }^{4,6}$, Morgan N Price ${ }^{4,6}$, \\ Zamin K Yang ${ }^{4,7}$, Huei-Che Bill Yen ${ }^{4,8}$, Christopher L Hemme ${ }^{3,4}$, Wenqiong Chen ${ }^{4,9}$, \\ Matthew W Fields, ${ }^{4,10}$, David A Stahl ${ }^{4,11}$, Jay D Keasling ${ }^{4,6,12}$, Martin Keller ${ }^{4,7}$, \\ Adam P Arkin ${ }^{4,6,13}$, Terry C Hazen ${ }^{4,5}$, Judy D Wall ${ }^{4,8}$ and Jizhong Zhou ${ }^{3,4}$ \\ ${ }^{1}$ Department of Civil and Environmental Engineering, The University of Tennessee, Knoxville, TN, USA; \\ ${ }^{2}$ Center for Environmental Biotechnology, The University of Tennessee, Knoxville, TN, USA; ${ }^{3}$ Department of \\ Botany and Microbiology, Institute for Environmental Genomics, Stephenson Research \& Technology Center \\ University of Oklahoma, Norman, OK, USA ${ }^{4}$ Virtual Institute for Microbial Stress and Survival, University of \\ Missouri-Columbia, Columbia, SC, USA $;{ }^{5}$ Earth Sciences Division, Lawrence Berkeley National Laboratory, \\ Berkeley, CA, USA; ${ }^{6}$ Physical Biosciences Division, Lawrence Berkeley National Laboratory, Berkeley, CA, \\ USA; ${ }^{7}$ Biosciences Division, Oak Ridge National Laboratory, Oak Ridge, TN, USA; ${ }^{8}$ Departments of \\ Biochemistry and Molecular Microbiology \& Immunology, University of Missouri-Columbia, Columbia, MO, \\ USA; ${ }^{9}$ Diversa Corp, San Diego, CA, USA; ${ }^{10}$ Department of Microbiology, Montana State University, Bozeman, \\ Montana, USA; ${ }^{11}$ Department of Civil and Environmental Engineering, University of Washington, Seattle, \\ WA, USA; ${ }^{12}$ Department of Chemical Engineering, University of California, Berkeley, CA, USA and \\ ${ }^{13}$ Department of Bioengineering, University of California, Berkeley, CA, USA
}

Sulfate-reducing bacteria have been extensively studied for their potential in heavy-metal bioremediation. However, the occurrence of elevated nitrate in contaminated environments has been shown to inhibit sulfate reduction activity. Although the inhibition has been suggested to result from the competition with nitrate-reducing bacteria, the possibility of direct inhibition of sulfate reducers by elevated nitrate needs to be explored. Using Desulfovibrio vulgaris as a model sulfate-reducing bacterium, functional genomics analysis reveals that osmotic stress contributed to growth inhibition by nitrate as shown by the upregulation of the glycine/betaine transporter genes and the relief of nitrate inhibition by osmoprotectants. The observation that significant growth inhibition was effected by $70 \mathrm{~mm} \mathrm{NaNO}$, but not by $70 \mathrm{~mm} \mathrm{NaCl}$ suggests the presence of inhibitory mechanisms in addition to osmotic stress. The differential expression of genes characteristic of nitrite stress responses, such as the hybrid cluster protein gene, under nitrate stress condition further indicates that nitrate stress response by $D$. vulgaris was linked to components of both osmotic and nitrite stress responses. The involvement of the oxidative stress response pathway, however, might be the result of a more general stress response. Given the low similarities between the response profiles to nitrate and other stresses, less-defined stress response pathways could also be important in nitrate stress, which might involve the shift in energy metabolism. The involvement of nitrite stress response upon exposure to nitrate may provide detoxification mechanisms for nitrite, which is inhibitory to sulfate-reducing bacteria, produced by microbial nitrate reduction as a metabolic intermediate and may enhance the survival of sulfate-reducing bacteria in environments with elevated nitrate level.

The ISME Journal (2010) 4, 1386-1397; doi:10.1038/ismej.2010.59; published online 6 May 2010

Subject Category: integrated genomics and post-genomics approaches in microbial ecology

Keywords: Desulfovibrio; nitrate; stress response; sulfate-reducing bacteria; functional genomics; systems biology

Correspondence: J Zhou, Department of Botany and Microbiology, Institute for Environmental Genomics (IEG), Stephenson Research \& Technology Center, University of Oklahoma, 101 David L. Boren Blvd., Norman, OK 73072, USA.

E-mail: jzhou@ou.edu

Received 5 February 2010; revised 26 March 2010; accepted 26 March 2010; published online 6 May 2010

\section{Introduction}

Exploitation of microbially mediated reduction of redox-sensitive metals has been proposed as a promising strategy to remediate metal-contaminated subsurface environments in situ (Valls and de Lorenzo, 2002; Wall and Krumholz, 2006). Owing 
to this ability to reduce and accumulate heavy metals and radionuclides (Jones et al., 1976; Lovley et al., 1993a; Chardin et al., 2002), sulfate-reducing bacteria (SRBs) have drawn particular attention for potential applications in heavy metal immobilization. It has been well documented that SRBs can reductively precipitate redox metals through enzymatic pathways (Lovley and Phillips, 1992; Abdelouas et al., 1998) or can simply precipitate metals as metallic sulfides. Enzymatic reduction of soluble metal oxyanions to insoluble forms has been specifically shown forDesulfovibrio spp. (Lovley et al., 1993b; Lloyd et al., 1999; Payne et al., 2002), which are the model SRBs most extensively studied for their bioremediation capacity. More importantly, SRB populations are also found to be significant members of microbial communities involved in such metal reduction and are ubiquitous even in extreme environments (Chang et al., 2001; Gillan et al., 2005; Bagwell et al., 2006; Fields et al., 2006). Therefore, stimulation of SRB activities has been considered as a useful approach for the immobilization of heavy metals and radionuclides (Landa, 2005; Lloyd and Renshaw, 2005).

To exploit SRB effectively for the remediation of heavy metal and radionuclide contaminated sites, it is important to understand the microbial responses to the adverse environmental factors commonly encountered in these subsurface environments. One such factor is the high nitrate concentration of many contaminated sites at the US nuclear weapon complexes managed by the Department of Energy (Riley and Zachara, 1992; NABIR, 2003). The presence of nitrate may pose a specific stress to SRB as nitrate has been observed to suppress sulfate reduction activity in situ (Jenneman et al., 1986; Davidova et al., 2001). Thus, it is important to examine the responses of sulfate-reducing microorganisms in metabolic and regulatory pathways following nitrate exposure to understand their defense mechanisms. Furthermore, as nitrate is a broadly available electron acceptor readily used by a large number of microorganisms in natural environments, nitrate reduction as an ecologically more competitive process could have major impacts on the survival and persistence of SRB in microbial communities, as well as on the functions of SRB in nitrate-impacted environments. Therefore, insights into the mechanisms of the ecological adaptability of SRB in nitrate-impacted environments would facilitate the development of strategies to monitor and predict the performance of these microorganisms in bioremediation (Hazen and Stahl, 2006).

In this report, we used Desulfovibrio vulgaris Hildenborough as a model organism to investigate the inhibition of sulfate reduction by nitrate as compared with other related stress conditions. Our results from physiological analyses indicate the presence of inhibitory mechanisms in addition to the expected osmotic stress responses. Subsequent functional studies revealed that nitrate stress response by $D$. vulgaris was linked to components of both osmotic and nitrite stress responses.

\section{Materials and methods}

High-throughput monitoring of cell growth with various stressor concentrations

The growth response of $D$. vulgaris cells to various concentrations of sodium nitrate $\left(\mathrm{NaNO}_{3}\right)$ or sodium chloride $(\mathrm{NaCl})$ was monitored using the Phenotype MicroArray platform (Biolog Inc., Hayward, CA, USA). Culture handling and instrument operation were carried out following a previously described procedure (Borglin et al., 2009). The OmniLog instrument was calibrated against $D$. vulgaris cell densities as measured by a spectrophotometer at $\mathrm{OD}_{600}$ and direct cell counts. All were comparable at $95 \%$ confidence interval (CI) for the exponential growth phase. Specifically, OL(Omnilog) readings were converted to cell density (cells $\mathrm{ml}^{-1}$ ) using the following experimentally determined linear expression $\left(r^{2}=0.933, n=37\right)$ : cell density $=2.34 \times 10^{7}$. $\mathrm{OL}+34.3$.

Impacts of osmoprotectants on growth responses to nitrate stress

Glycine betaine was selected as the osmoprotectant to test the presence of potential osmotic stress responses when $D$. vulgaris was exposed to high nitrate levels as this osmolyte had been shown to protect $D$. vulgaris from salt stress (Mukhopadhyay et al., 2006). Initially, glycine betaine was added into the Yen45 defined medium (Bender et al., 2007) to a final concentration of $2 \mathrm{mM}$, together with additional $\mathrm{NaNO}_{3}$ at 100 or $200 \mathrm{~mm}$. This medium has fewer precipitates that interfere with optical density determinations than does the LS4D medium (Mukhopadhyay et al., 2006). Controls without glycine betaine and those without either glycine betaine or nitrate were also compared. Following a $2 \%(\mathrm{v} / \mathrm{v})$ inoculation with a late-log phase culture $\left(\mathrm{OD}_{600} \sim 0.8-0.9\right)$, growth was monitored by optical density measurements at $600 \mathrm{~nm}$.

\section{Biomass production for microarray and proteomics} analysis

Cultures for biomass production were initiated with $10 \%(\mathrm{v} / \mathrm{v})$ inocula from stocks of $D$. vulgaris frozen at $-80{ }^{\circ} \mathrm{C}$ (fully grown cells in LS4D with $10 \%(\mathrm{v} / \mathrm{v})$ glycerol) into LS4D medium as previously described (Mukhopadhyay et al., 2006). All production cultures were grown in triplicate (three control cultures and three stressed cultures). When the production cultures reached an $\mathrm{OD}_{600}$ of $0.3,50 \mathrm{ml}$ was taken from each replicate culture as the T0 samples. Once the T0 samples were taken, degassed $\mathrm{NaNO}_{3}$ solution was immediately added to the three treatment cultures to a final concentration of $105 \mathrm{mM}$ (6500 p.p.m. nitrate, which was shown to inhibit the 
growth rate of the log-phase cultures by approximately $50 \%$ ), and an equivalent volume of sterile, distilled, degassed water was added to each control culture. Culture samples of $50 \mathrm{ml}$ were collected from each culture at $30,60,120$ and $240 \mathrm{~min}$ post-addition while cells were still in exponential growth phase. To minimize mRNA or protein changes during sample collection and processing, cell samples were rapidly chilled and pelleted using a previously described method (Mukhopadhyay et al., 2006). The final pellet was flash-frozen in liquid nitrogen and stored at $-80{ }^{\circ} \mathrm{C}$ for microarray analysis.

The same procedure was followed to collect the biomass for proteomics analysis, with the exception that sampling from the production cultures was conducted at only two time points. Briefly, when the production cultures reached an $\mathrm{OD}_{600}$ of ca. $0.3,100 \mathrm{ml}$ of sample was taken from each triplicate culture as the T0 samples. Following nitrate $(105 \mathrm{mM})$ addition, $100 \mathrm{ml}$ each from the three control cultures and $100 \mathrm{ml}$ each from the three stressed cultures were collected at $240 \mathrm{~min}$ post-exposure as the T1 sample. Culture samples from the triplicate treatment or control cultures at each time point were subsequently pooled to provide adequate biomass for protein extraction. Cell mass from the four pooled culture samples, $\mathrm{T} 1$ and T0 for the treatment and control, respectively, were harvested using the same procedure as described above for microarray analysis. The final pellet was flash-frozen in liquid nitrogen and stored at $-80{ }^{\circ} \mathrm{C}$ until proteomics analysis.

\section{Microarray transcriptomic analysis}

A previously described whole-genome oligonucleotide DNA microarray (He et al., 2006), covering more than $98.6 \%$ of the annotated protein-coding sequences of the $D$. vulgaris genome, was used for global transcriptional analysis of nitrate stress response. The accuracy of the microarrays in global transcriptional profiling has been extensively tested and validated in previous studies on stress response pathways in $D$. vulgaris (Clark et al., 2006; He et al., 2006). All microarray procedures including the extraction and labeling of nucleic acids, microarray hybridization and washing, and data analysis were performed using previously published protocols (He et al., 2006). Total RNA extraction, purification and labeling were performed independently on each cell sample using previously described protocols (He et al., 2006; Butler et al., 2007). Each replicate sample consisted of cells from 300-ml cultures. Labeling of cDNA targets from purified total RNA was carried out using the reverse transcriptase reaction with random hexamer priming, and the fluorophore Cy5-dUTP (Amersham Biosciences, Piscataway, NJ, USA). Genomic DNA was extracted from $D$. vulgaris cultures at stationary phase and labeled with the fluorophore Cy3-dUTP (Amersham
Biosciences). To hybridize a single glass slide, the Cy5-dUTP-labeled cDNA targets obtained from stressed or non-stressed control cultures were mixed with the Cy3-dUTP-labeled genomic DNA. After washing and drying, the microarray slides were scanned using the ScanArray Express microarray analysis system (Perkin Elmer, Fremont, CA, USA). The fluorescent intensity of both Cy5 and Cy3 fluorophores was analyzed with ImaGene software version 6.0 (Biodiscovery, Marina Del Rey, CA, USA). Log ratios of differential gene expression between treatment and control cultures were determined using previously described data processing and analysis methods, and statistical significance was assessed using standard $Z$-scores (Chhabra et al., 2006). Pairwise correlation coefficients between any two transcriptional profiles were computed with the centered Pearson's correlation using the entire transcriptional expression profiles obtained by the $D$. vulgaris microarray. Color heat map representations comparing gene expression under various growth conditions were generated using the software JColorGrid (Joachimiak et al., 2006). The microarray results were deposited at the GEO database with the accession number GSE20079.

\section{Three-dimensional nano LC-MS/MS proteomics} analysis of nitrate-stressed biomass

Total protein extracted and treated from the control and stressed samples was used for fractionation by three-dimensional liquid chromatography, followed by tandem mass spectrometry analysis to determine the protein identities, as described previously (Wei et al., 2005). The relative abundance of proteins in each sample was estimated on the basis of the hypothesis that the more abundant a peptide ion is in a mixture, the more likely it is that the peptide ion is sampled during the course of a tandem mass spectrometry experiment (Wolters et al., 2001; Liu et al., 2004). Accordingly, the total numbers of qualified spectral counts represented the relative abundance of each protein under a specific condition. To identify proteins for which there were significant changes under certain conditions, the statistical 'local-pooled-error' test (Jain et al., 2003) was used. Only protein changers with a $P$-value of less than 0.05 were considered to be significant.

\section{Results}

Growth inhibition of D. vulgaris by nitrate

The inhibitory effect of nitrate was evaluated by monitoring the growth of $D$. vulgaris in the presence of various concentrations of sodium nitrate. Although a slow-growth phase (with no detectable growth) of approximately $20 \mathrm{~h}$ was observed in control cultures without nitrate addition, an extended phase of slow growth followed by normal growth was observed with increasing concentrations of nitrate in the culture medium, indicative of 

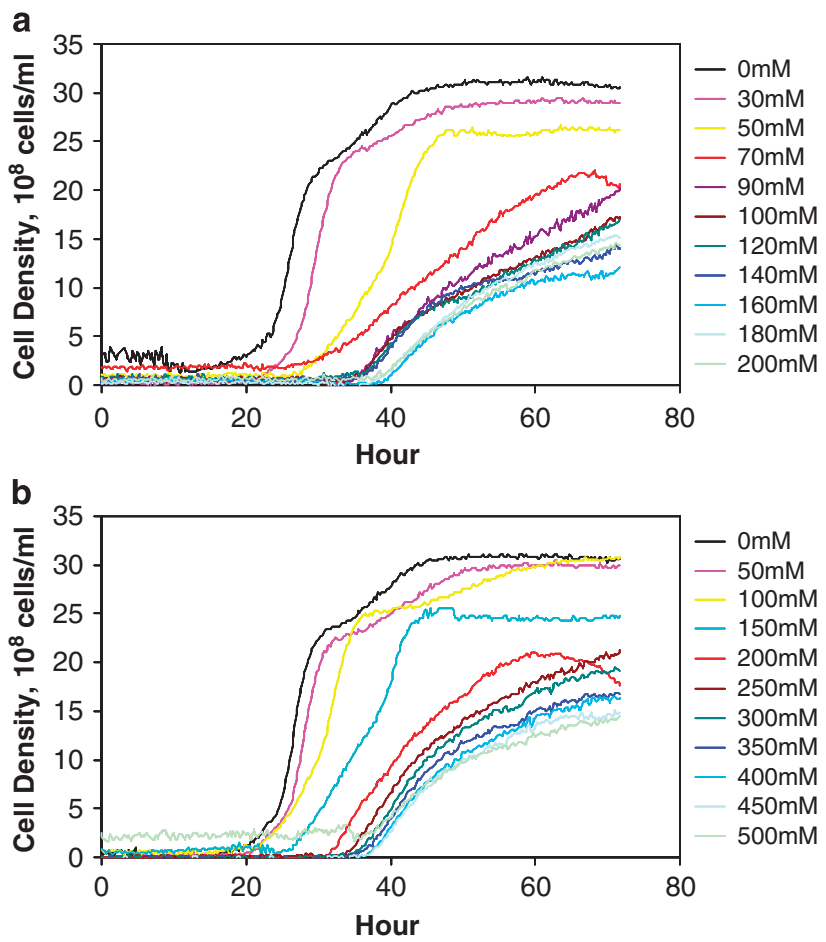

Figure 1 Growth response of Desulfovibrio vulgaris to varying concentrations of (a) $\mathrm{NaNO}_{3}$ or (b) $\mathrm{NaCl}$.

a moderate inhibitory effect (Figure 1a). A more severe inhibition pattern, characterized by a sharp decrease in growth rate accompanied by an increasingly longer slow-growth phase, was apparent when the nitrate concentration reached $70 \mathrm{~mm}$, as indicated by the reduced slope of the growth curve (Figure 1a).

As sodium nitrate is an ionic solute, high concentrations of nitrate are expected to result in osmotic stress as a non-specific inhibitory mechanism. To identify any inhibitory effects specific to nitrate, a comparison was made between the growth responses of $D$. vulgaris to sodium nitrate versus sodium chloride, which are known to cause osmotic stress. In sharp contrast to the $70 \mathrm{mM}$ sodium nitrate addition needed for growth inhibition, a significant decrease in the growth rate of $D$. vulgaris was observed only when $200 \mathrm{~mm}$ sodium chloride was added into the LS4D medium (Figure 1b). These results suggest that sodium nitrate inhibition resulted from at least some interactions specific to nitrate and not simply from a salt-induced osmotic effect.

\section{Global transcriptomic analysis of nitrate stress}

To understand the mechanisms of nitrate inhibition and the potential response pathways used by $D$. vulgaris cells to alleviate nitrate stress, microarray experiments were carried out to compare global gene expression profiles between nitratestressed D. vulgaris cultures and control cultures without nitrate exposure. D. vulgaris cells were challenged by a nitrate level of $105 \mathrm{mM}$, which was effective in inhibiting, but not eliminating, cell growth in log-phase cultures.

Changes in the gene expression profile were observed at $30 \mathrm{~min}$ following nitrate exposure and peaked at $120 \mathrm{~min}$, with 298 genes being differentially expressed, either up or down, greater than twofold (Supplementary Figure S1). A similar number of genes (288) remained differentially regulated at $240 \mathrm{~min}$. It is noted that the number of genes with reduced expression level considerably exceeded the number of genes with increased expression at 30,60 and $120 \mathrm{~min}$, consistent with the inhibitory effect of nitrate observed in the growth study (Figure 1). As the number of downregulated genes peaked at $120 \mathrm{~min}$, the number of up-regulated genes, however, continued to rise throughout the duration of the experiment, which is indicative of an active response to nitrate treatment following the initial inhibition.

\section{Effects of osmoprotectants on growth inhibition by nitrate}

Given the presence of osmotic stress at high nitrate concentrations, indications of osmotic stress response following nitrate exposure were examined. Indeed, transcriptional profiling showed an increase in the gene expression of the periplasmic-binding protein of the glycine/betaine/proline ABC transporter (DVU2297; $\log _{2} R=1.6$ at $240 \mathrm{~min}$ ), although not the putative permease or ATP binding protein. As glycine betaine is a known osmoprotectant (Cayley and Record, 2003) and has been shown to relieve osmotic stress in D. vulgaris (Mukhopadhyay et al., 2006), the up-regulation of this gene supports the expected overlap between osmotic stress and nitrate stress. To further confirm that nitrate inhibition is associated with osmotic stress, growth was monitored following the addition of glycine betaine as an osmoprotectant into $D$. vulgaris cultures in nitrate-supplemented defined medium (Figure 2).

Similar to stress-inducing concentrations of $\mathrm{NaCl}$, elevated $\mathrm{NaNO}_{3}$ concentrations resulted in a prolonged lag phase and significantly reduced the final cell density. The addition of glycine betaine led to the complete recovery of the final cell density in D. vulgaris cultures exposed to $100 \mathrm{mM} \mathrm{NaNO}_{3}$, but provided only a $16 \%$ reduction of the lag phase (Figure 2a), which is in contrast to the nearcomplete reversal of growth inhibition by glycine betaine in $\mathrm{NaCl}$ stress (Mukhopadhyay et al., 2006). The inability of glycine betaine to relieve nitrate stress entirely indicates that osmotic stress does not account for all the inhibition of cellular activities by nitrate stress.

In contrast, growth inhibition by $200 \mathrm{mM} \mathrm{NaNO}_{3}$ was more significantly relieved by the inclusion of glycine betaine in the medium, with the lag phase shortened from approximately 300 to $100 \mathrm{~h}$ 

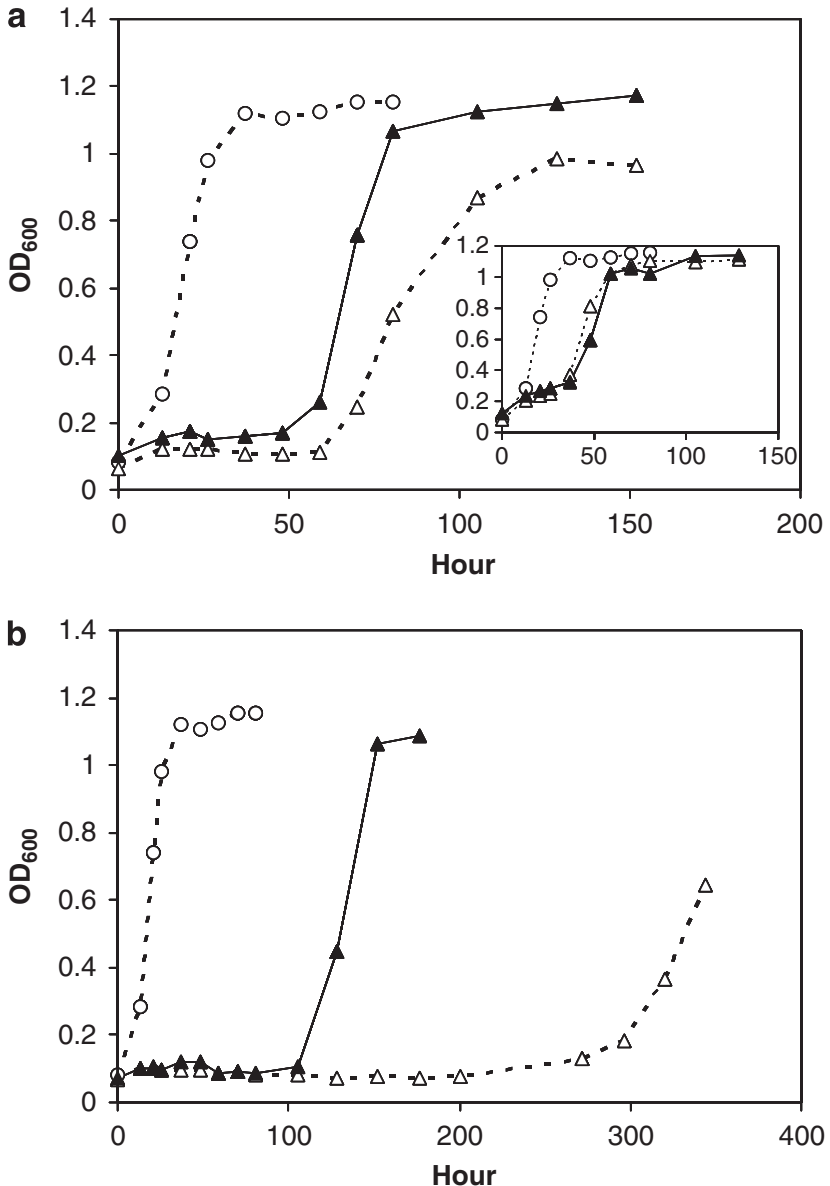

Figure 2 Impact of glycine betaine on the growth of $D$. vulgaris exposed to $100 \mathrm{mM}$ (a) and $200 \mathrm{mM}(\mathbf{b})$ sodium nitrate. The inset in panel a shows the growth of $D$. vulgaris when 2 mM sodium nitrite was in place of sodium nitrate. D. vulgaris cultures were inoculated to a defined medium (Control, open circles), medium supplemented with sodium nitrate / nitrite only (open triangles), or medium supplemented with sodium nitrate / nitrite plus $2 \mathrm{mM}$ glycine betaine as an osmoprotectant (closed triangles). Note different time scales on graphs. Results were typical of three experiments.

(Figure 2b). This observation was likely the result of the increasing importance of osmotic stress with higher levels of nitrate. Nonetheless, only partial relief of nitrate stress was provided by the addition of osmoprotectant, further suggesting the presence of additional sources of growth inhibition that were specific to nitrate stress, but not osmotic stress.

\section{Genes involved in methyl/SAM metabolism}

In nitrate-stressed $D$. vulgaris, a group of genes involved in the methyl metabolism were among those with the greatest increases in expression (Supplementary Table S1), including metF (DVU0997), metE (DVU3371) and ahcY (DVU0607). All these genes have functions in the metabolism of methionine and regeneration of $S$-adenosylmethionine (SAM), a major methyl donor in various cellular processes (Wang and Frey, 2007). A careful examination of the genes up-regulated under nitrate stress further revealed the increased expression of the gene encoding another key enzyme in SAM biosynthesis, $S$-adenosylmethionine synthetase MetK (DVU2449; $\log _{2} R=1.7$ ). From the co-expression patterns of all these genes (Supplementary Figure S2), scattered across the genome, we infer the presence of a regulatory mechanism that might be involved in the increased turnover of SAM.

Interestingly, the enzyme activating the pyruvate formate-lyase (DVU2825), which was also among the most up-regulated genes under nitrate stress (Supplementary Table S1), has been shown to require the methyl donor SAM in other bacteria (Chase and Rabinowitz, 1968; Knappe and Schmitt, 1976), providing a potential link between energy metabolism and methyl/SAM metabolism (Supplementary Figure S2).

Genes involved in energy metabolism

Nitrate does not support the growth of $D$. vulgaris as an electron acceptor or nitrogen source (Haveman et al., 2004, 2005). However, in many other anaerobes nitrate metabolism is directly linked to energy metabolism via multiple redox reactions (Moura et al., 1997). Thus, the involvement of genes in energy metabolism was investigated when elevated nitrate constituted a stress condition. Transcriptional analysis indicated that a small number of genes with functions in energy metabolism were among those highly up-regulated under nitrate stress, such as the genes related to the catabolism of pyruvate as a key metabolic intermediate: a pyruvate formate-lyase (DVU2824) and its activating enzyme (DVU2825) (Supplementary Table S1). These two genes form an operon with two other genes encoding a tripartite ATP-independent periplasmic (TRAP) dicarboxylate transporter (DVU2822-2825). In addition, a formate dehydrogenase gene cluster (DVU0586-0588) had increased expression under nitrate stress (data not shown). The composite of these differentially expressed genes appears to be consistent with an increased flow of reducing equivalent cycling through formate as a metabolic intermediate, as suggested under certain growth conditions (He et al., 2006; Pereira et al., 2008).

The gene encoding the hybrid cluster protein (DVU2543), which was suggested to be involved in the response to reactive nitrogen species generated in nitrate metabolism in other microorganisms (van den Berg et al., 2000; Wolfe et al., 2002), was also up-regulated $\left(\log _{2} R=1.8\right)$. It is noted that this gene was among the most highly up-regulated $\left(\log _{2}\right.$ $R=6.4$ ) under nitrite stress (Haveman et al., 2004; He et al., 2006). The iron-sulfur cluster-binding protein, predicted to be encoded promoter distal in the same operon (DVU2544), was also increased in expression ( $\log _{2} R=1.9$ ), representing a shared response to nitrate and nitrite stress (Table 1). Nonetheless, the differential expression of the hybrid 
Table 1 Comparison of the gene expression of selected gene groups in response to $\mathrm{NaNO}_{3}, \mathrm{NaNO}_{2}$ and $\mathrm{NaCl}$ in $D$. vulgaris ${ }^{\mathrm{a}}$

\begin{tabular}{|c|c|c|c|c|}
\hline \multirow[t]{2}{*}{ Gene ID } & \multicolumn{3}{|c|}{$\log _{2}$ ratio of transcriptional response ${ }^{\mathrm{b}}$} & \multirow[t]{2}{*}{ TIGR Annotation } \\
\hline & $\mathrm{NaNO}_{3}{ }^{\mathrm{c}}$ & $\mathrm{NaNO}_{2}{ }^{\mathrm{c}}$ & $\mathrm{NaCl}^{\mathrm{c}}$ & \\
\hline \multicolumn{5}{|c|}{ Methyl metabolism } \\
\hline DVU0606 & 2.5 & 2.0 & -1.0 & Regulator/methyltransferase, UbiE/COQ5 family \\
\hline DVU0607 & 2.7 & 2.4 & 1.1 & Adenosylhomocysteinase, AhcY \\
\hline DVU0997 & 2.9 & 2.2 & 0.6 & 5,10-Methylenetetrahydrofolate reductase, MetF \\
\hline DVU2449 & 1.7 & 2.1 & -1.3 & $S$-Adenosylmethionine synthetase, MetK \\
\hline DVU3371 & 2.7 & 3.8 & -1.4 & 5-Methyltetrahydropteroyltriglutamate-homocysteine $S$-methyltransferase, MetE \\
\hline \multicolumn{5}{|c|}{ Carbon metabolism } \\
\hline DVU2822 & 3.4 & 0.9 & 1.5 & TRAP dicarboxylate family transporter \\
\hline DVU2823 & 1.8 & 0.4 & 1.9 & TRAP dicarboxylate transporter family protein \\
\hline DVU2824 & 2.5 & 0.5 & 0.9 & Formate acetyltransferase \\
\hline DVU2825 & 2.9 & 0.6 & 0.7 & Pyruvate formate-lyase 1 activating enzyme \\
\hline DVU0586 & 2.5 & 0.5 & -1.4 & Hypothetical protein \\
\hline DVU0587 & 1.5 & 0.7 & -1.8 & Formate dehydrogenase, alpha subunit, selenocysteine-containing \\
\hline DVU0588 & 1.6 & 0.3 & -1.3 & Formate dehydrogenase, beta subunit, putative \\
\hline DVU1569 & 0.8 & 1.1 & 0.4 & Pyruvate ferredoxin oxidoreductase, alpha subunit PorA \\
\hline DVU1570 & -0.5 & 1.3 & -1.2 & Pyruvate ferredoxin oxidoreductase, beta subunit PorB \\
\hline \multicolumn{5}{|c|}{ Nitrogen metabolism } \\
\hline DVU2543 & 1.8 & 5.7 & -1.2 & Hybrid cluster protein \\
\hline DVU2544 & 1.9 & 6.2 & 0.5 & Iron-sulfur cluster-binding protein \\
\hline DVU0624 & 0.3 & 4.4 & -1.3 & NapC/NirT cytochrome $c$ family protein \\
\hline DVU0625 & 0.7 & 4.1 & -1.3 & Cytochrome $c$ nitrite reductase, catalytic subunit NrfA \\
\hline
\end{tabular}

Abbreviation: TRAP, tripartite ATP-independent periplasmic.

${ }^{\mathrm{a} G e n e}$ expression profiles following $\mathrm{NaNO}_{3}(105 \mathrm{mM}), \mathrm{NaNO}_{2}(2.5 \mathrm{mM})$ and $\mathrm{NaCl}(250 \mathrm{mM})$ treatment in $D$. vulgaris were obtained from this study, He et al., 2006, and Mukhopadhyay et al., 2006, respectively.

${ }^{b}$ Expression ratios represent the highest levels of differential gene expression throughout the time course (240 min) of the stress exposure. Expression levels were obtained at the same time points from both the treatment and control cultures for the calculation of the expression changes resulting from the stressor. Positive $\log _{2}$ (Expression Ratio) values denote increases in expression level and negative values indicate decreases in expression level. Values with $\mathrm{Z}>2$ are shown in boldface type.

'The treatment cultures received addition of $\mathrm{NaNO}_{3}, \mathrm{NaNO}_{2}$ or $\mathrm{NaCl}$, and the control cultures received none.

Table 2 Effect of nitrate exposure on the transcriptional responses of Desulfovibrio vulgaris genes in the predicted PerR regulon ${ }^{\mathrm{a}}$

\begin{tabular}{|c|c|c|c|c|c|}
\hline \multirow[t]{2}{*}{ Gene ID } & \multirow[t]{2}{*}{ Description } & \multicolumn{4}{|c|}{ 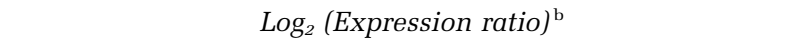 } \\
\hline & & $30 \mathrm{~min}$ & $60 \mathrm{~min}$ & $120 \min$ & $240 \mathrm{~min}$ \\
\hline DVU0772 & Hypothetical protein & 0.1 & 0.7 & 2.0 & 2.4 \\
\hline DVU2247 & Alkyl hydroperoxide reductase $\mathrm{C}, a h p C$ & 0.2 & 0.5 & 0.7 & 1.6 \\
\hline DVU2318 & Rubrerythrin, putative, rbr2 & 0.4 & 0.6 & 0.9 & 2.2 \\
\hline DVU3093 & Rubredoxin-like protein, $r d l$ & -0.2 & 0.0 & 0.8 & 1.2 \\
\hline DVU3094 & Rubrerythrin, rbr & -0.2 & -0.1 & -0.3 & 0.7 \\
\hline DVU3095 & Peroxide-responsive regulator PerR & -0.5 & 0.0 & 0.8 & 1.4 \\
\hline
\end{tabular}

aPredicted PerR regulon from Rodionov et al., 2004.

${ }^{b}$ Expression ratios represent the levels of gene expression at various time points following the addition of 105 mM nitrate into cultures compared with controls without nitrate addition. Expression levels were obtained at the same time points from both the treatment and control cultures for the calculation of the expression changes resulting from the stressor. Positive $\log _{2}$ (Expression Ratio) values denote increases in expression level and negative values indicate decreases in expression level. Values with $\mathrm{Z}>2$ are shown in boldface type.

cluster protein operon was much weaker in response to nitrate than in response to nitrite. No significant changes in gene expression were observed in other known genes participating in nitrogen metabolism.

Another highly up-regulated gene with annotated functions in energy metabolism encodes a putative rubrerythrin (DVU2318) (Supplementary Table S1), which is predicted to be under the regulation of the peroxide-responsive regulator (PerR) (Rodionov et al., 2004). A survey of the gene expression profile indicated that all genes in the predicted PerR regulon had increased expression to various extents under nitrate stress (Table 2). However, comparison of gene expression profiles found that the PerR regulon was consistently up-regulated throughout different stress conditions (Chhabra et al., 2006; He et al., 2006; Mukhopadhyay et al., 2006, 2007), indicating that the increased expression of the PerR regulon was likely a part of the general stress response. 
Proteomics analysis of nitrate stress response

Liquid chromatography-mass spectrometry proteomics analysis of the stress response to nitrate in the wild-type strain was performed to complement transcriptional analysis. Ribosomal proteins were among the most downregulated, consistent with transcriptional analysis and growth inhibition observed with exposure to elevated nitrate (Table 3). Proteomics results also confirmed the up-regulation of the glycine/betaine/proline ABC transporter (DVU2297) and MetE (DVU3371), which is a key enzyme in the methyl/SAM metabolic pathway (Supplementary Figure S2). A phi coefficient of correlation of 0.6 was achieved for genes/proteins with significant changes in both transcriptional and proteomics analyses, which is indicative of the good agreement on the direction of regulation at both the messenger RNA and protein levels. This is also largely consistent with previous comparisons between transcriptional and proteomics profiles in D. vulgaris (Chhabra et al., 2006;
Mukhopadhyay et al., 2006), confirming the validity of the microarray technique and subsequent transcriptional analysis for making regulatory event inferences in D. vulgaris.

\section{Comparison of nitrate stress response with other stress conditions}

The above analyses show that nitrate stress shared with two related stresses, $\mathrm{NaCl}$ stress and nitrite stress, similar patterns of gene expression in a number of genes, including the glycine/betaine/ proline ABC transporter (DVU2297) and hybrid cluster protein (DVU2543) genes. To further determine the potential correlations in gene expression between nitrate, nitrite and $\mathrm{NaCl}$ stress responses in $D$. vulgaris, all genes with significant changes in expression were identified at $30 \mathrm{~min}$ following stress exposure, which corresponds to the earliest post-stress time point and likely represents the most direct stress responses in the early phase of the

Table 3 Comparison of transcript abundance with corresponding protein levels following nitrate exposure in $D$. vulgaris ${ }^{\mathrm{a}}$

\begin{tabular}{|c|c|c|c|}
\hline \multirow[t]{2}{*}{ Gene ID } & \multirow[t]{2}{*}{ Description } & \multicolumn{2}{|c|}{$\log _{2}(\text { Expression Ratio })^{\mathrm{b}}$} \\
\hline & & $m R N A^{\mathrm{c}}$ & Protein $^{\mathrm{d}}$ \\
\hline DVU0470 & Tryptophan synthase, beta subunit, $\operatorname{trp} B-2$ & $+1.1^{60}$ & +0.8 \\
\hline DVU0764 & DNA-binding protein HU, hup-2 & -1.1 & -1.3 \\
\hline DVU0777 & ATP synthase, $\mathrm{F}_{1}$ alpha subunit, atp $A$ & $-1.1^{120}$ & -0.4 \\
\hline DVU0873 & Translation elongation factor Ts, $t s t$ & -1.4 & +1.1 \\
\hline DVU1077 & Inner membrane protein, $60 \mathrm{kDa}$, yidC & $-1.3^{120}$ & -1.0 \\
\hline DVU1089 & Alanyl-tRNA synthetase, alaS & -1.3 & +1.4 \\
\hline DVU1295 & Sulfate adenylyltransferase, sat & +1.4 & +0.4 \\
\hline DVU1300 & Translation elongation factor $\mathrm{G}$, fus $A-1$ & -1.3 & +0.5 \\
\hline DVU1303 & Ribosomal protein $\mathrm{L} 3, \mathrm{rplC}$ & -1.7 & -0.7 \\
\hline DVU1306 & Ribosomal protein L2, rplB & -1.5 & -1.0 \\
\hline DVU1308 & Ribosomal protein L22, rplV & -1.7 & -0.9 \\
\hline DVU1317 & Ribosomal protein S8, rpsH & -1.3 & -0.9 \\
\hline DVU1326 & Ribosomal protein S13, rpsM & -1.2 & -1.3 \\
\hline DVU1434 & Hypothetical protein & -1.1 & +2.0 \\
\hline DVU1443 & Flagellar hook protein FlgE, flgE & $-1.4^{120}$ & -2.4 \\
\hline DVU1575 & Ribose-phosphate pyrophosphokinase, prsA & -1.4 & +1.5 \\
\hline DVU1636 & Inorganic pyrophosphatase, manganese-dependent, $p p a C$ & +1.2 & +0.7 \\
\hline DVU1896 & Ribosomal protein S20, rpsT & -2.1 & -1.3 \\
\hline DVU2105 & Hypothetical protein & $-1.6^{30}$ & -0.7 \\
\hline DVU2108 & MTH1175-like domain family protein & $+1.1^{30}$ & +0.6 \\
\hline DVU2215 & RNA-binding protein & $-1.4^{60}$ & +0.8 \\
\hline DVU2289 & Hydrogenase, CooX subunit, putative, $b 2488$ & $-1.1^{120}$ & -2.0 \\
\hline DVU2297 & Glycine/betaine/L-proline ABC transporter, periplasmic-binding protein & +1.6 & +0.6 \\
\hline DVU2347 & Acetylornithine aminotransferase, $\arg D$ & +1.4 & +0.8 \\
\hline DVU2364 & Aminotransferase, classes I and II & $-1.2^{120}$ & -0.8 \\
\hline DVU2927 & Ribosomal protein L7/L12, rplL & $-1.5^{120}$ & +0.9 \\
\hline DVU3228 & Chemotaxis protein CheY, cheY-3 & $+1.0^{120}$ & +1.3 \\
\hline DVU3371 & 5-Methyltetrahydropteroyltriglutamate-homocysteine S-methyltransferase, metE & +2.7 & +0.7 \\
\hline
\end{tabular}

${ }^{a}$ Genes with significant changes at both the mRNA and protein levels (absolute value of $Z>2$ ) subsequent to nitrate treatment were selected for comparison.

${ }^{b}$ Expression ratios represent the levels of expression following the addition of $105 \mathrm{~mm}$ nitrate into cultures compared with controls without nitrate addition. Expression levels were obtained at the same time points from both the treatment and control cultures for the calculation of the expression changes resulting from the stressor. $\log _{2}$ (Expression Ratio) values greater than 0 denote increases in expression level and values less than 0 indicate decreases in expression level.

${ }^{\mathrm{c} T r a n s c r i p t}$ abundance was determined from cDNA microarray analysis. Transcriptional expression ratios (log ${ }_{2} \mathrm{R}$ ) are shown for genes with $\mathrm{Z}>2$ (absolute value) at $240 \mathrm{~min}$ following nitrate treatment unless otherwise indicated. For genes with $\mathrm{Z}<2$ (absolute value) at 240 min, data are shown for a different time point (min; appears as an italic superscript).

dProtein abundance was determined from MS-MS proteomics analysis of protein extracts from cell samples subjected to 240-min of nitrate treatment. Protein abundance ratios $\left(\log _{2} \mathrm{R}\right)$ are shown for genes with $\mathrm{Z}>2$ (absolute value) at 240 min following nitrate addition. 
stress experiments. Genes with changes in expression at later post-stress time points, however, might not necessarily be representative of nitrate-specific responses. Instead, these genes could be involved in general stress response subsequent to the nitratespecific primary responses, such as the genes characteristic of the general oxidative stress responses in the PerR regulon discussed above, which were significantly upregulated at later time points during the experimental period (Table 2).

It is revealed that there were variable numbers of differentially expressed genes in response to each stress, from 40 in nitrate stress and 60 in salt stress (Mukhopadhyay et al., 2006), to 261 in nitrite stress (He et al., 2006) (Supplementary Figure S3). The numbers of differentially expressed genes in common between these experiments were very few, with ten between nitrite and $\mathrm{NaCl}$, six between nitrate and nitrite, one between nitrate and $\mathrm{NaCl}$, and none among all three stress responses. Thus, when considering common genes with significant change in expression at the time point when the stress response was most expected $(30 \mathrm{~min})$, it is evident that there was little similarity between these stress responses.

To further examine the presence of stress response pathways common between nitrate stress and various other stress conditions, analyses of gene expression overlap proportions and correlations were performed across all pairs of time points in eight stress responses, including nitrate (this study), nitrite (He et al., 2006), $\mathrm{NaCl}$ and $\mathrm{KCl}$
(Mukhopadhyay et al., 2006), heat shock (Chhabra et al., 2006), low oxygen (1000 p.p.m.) (Mukhopadhyay et al., 2007), high oxygen (air) (Mukhopadhyay et al., 2007) and alkaline stress (Stolyar et al., 2007). The highest values for gene overlap proportions (Figure 3) and gene expression correlations (Supplementary Figure S4) were observed between time points of the same stress response, as expected. Considering comparisons across different stress responses at $30 \mathrm{~min}$ post-stress, the two salt stresses $\mathrm{NaCl}$ and $\mathrm{KCl}$ showed the largest gene expression overlap proportions among all experimental pairs (excluding comparisons of time points from the same experiment) (Figure 3) and the highest correlation of 0.71 at 30 min (Supplementary Figure S4). The heat shock and high oxygen (air) stress exhibited the second largest overlap proportion and a correlation of 0.51 at $30 \mathrm{~min}$ (Figure 3 and Supplementary Figure S4), indicative of the similarities in stress response. It is evident that stress pairs showing the most gene expression overlap and highest gene expression correlations did so at all time points following the stress treatment. In contrast, the comparisons between nitrate, nitrite and $\mathrm{NaCl}$ showed minimal gene overlap proportions and gene expression correlations (Figure 3 and Supplementary Figure S4). For example, the gene expression correlation at $30 \mathrm{~min}$ for nitrate and nitrite was 0.08 , for nitrate and $\mathrm{NaCl} 0.11$, and for nitrite and $\mathrm{NaCl} 0.19$. Slightly better gene expression overlap proportions were observed between the last nitrate stress time point at $240 \mathrm{~min}$ and selected nitrite stress time
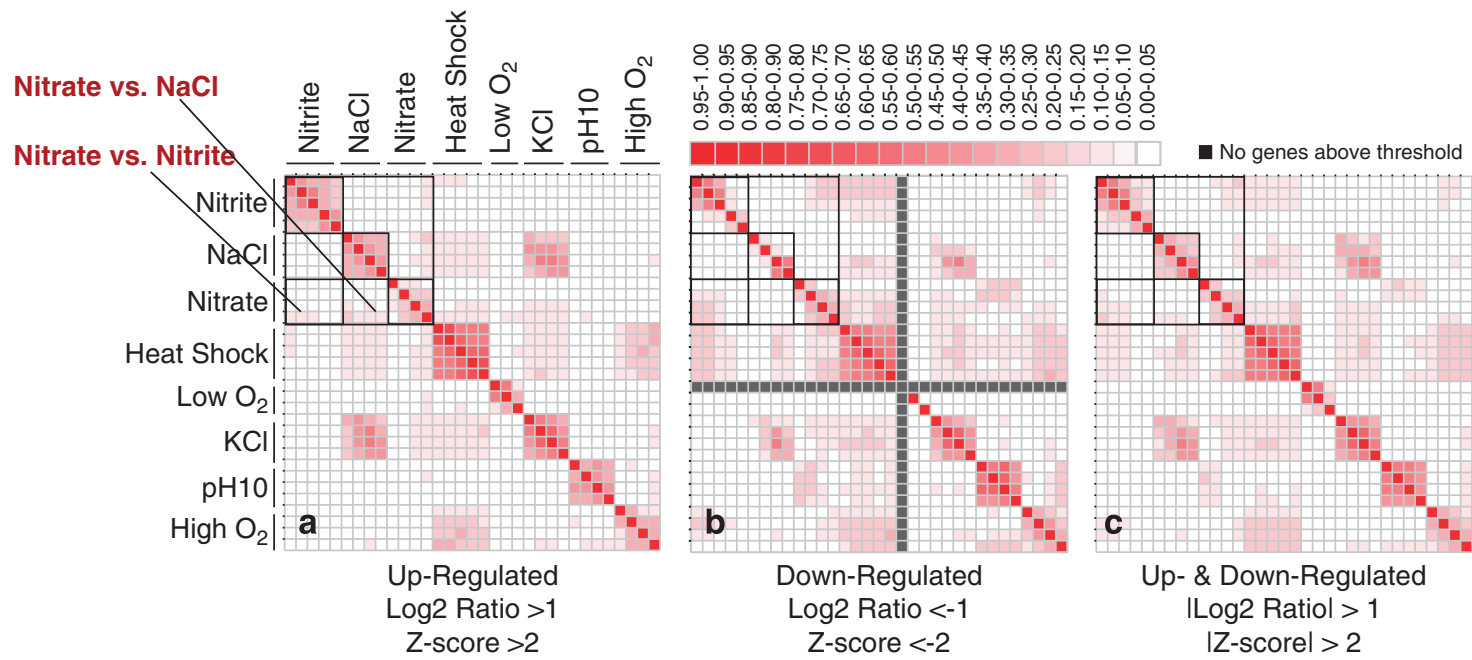

Figure 3 Gene expression overlap proportions between experimental time points of eight different stress conditions for $D$. vulgaris, including nitrate, nitrite, $\mathrm{NaCl}$, KCl, heat shock, low $\mathrm{O}_{2}(1000 \mathrm{ppm})$, high $\mathrm{O}_{2}$ (air) and alkaline (pH 10) stress. Shown are overlap proportions for genes in three categories: (a) up-regulated; (b) down-regulated; and (c) both up- and down-regulated. The gene expression overlap proportion between the two transcriptional profiles was computed as the number of genes above the threshold, i.e. Z-score and $\log _{2}$ Ratio, common between a pair of transcriptional profiles normalized by the root of the product of the number of genes above threshold in each transcriptional profile. The nitrate, nitrite and $\mathrm{NaCl}$ pairwise comparisons are in the top left corner of the heatmaps and are outlined in the black frame. Each square represents the gene expression overlap proportion of one pairwise comparison between two experiment time points. Time point increments for each stress condition progress left to right horizontally and top to bottom vertically from $30 \mathrm{~min}$ to $240 \mathrm{~min}$ post stress. Solid black squares indicate cases where one or both of the experimental time points being compared had no genes with significant change in expression. The bright red squares along the diagonal correspond to the greater proportions of common genes between time points within the same experiment. 
points. Similarly, the last nitrate stress time point had low overlap of gene expression with several $\mathrm{NaCl}$ time points. Since the last time point in the nitrate stress may not represent a primary response to this stress but secondary effects, these low similarity measures do not support similarity between the nitrate, nitrite and $\mathrm{NaCl}$ responses.

\section{Discussion}

Nitrate is a common co-contaminant in the subsurface environments impacted by radionuclides and heavy metals (Brooks, 2001). Nitrate inhibition of metal-reducing microbial populations, such as the SRB, hinders bioremediation efforts exploiting these microbial biocatalysts (Abdelouas et al., 1998; Finneran et al., 2002; Istok et al., 2004; Nyman et al., 2006). However, the persistence of sulfate-reducing bacteria at contaminated sites with high nitrate levels suggested the presence of potential resistance mechanisms (Gu et al., 2005; Bagwell et al., 2006; Fields et al., 2006), which were explored in this study using physiological and genomics approaches.

Growth inhibition by nitrate in the form of osmotic stress was demonstrated by the up-regulation of the glycine/betaine transporter genes and the relief of nitrate inhibition by osmoprotectant (Figure 2). However, osmotic stress response is not likely the only pathway contributing to the inhibitory effect of nitrate, given the minimal similarity in the transcriptional profiles between nitrate stress and $\mathrm{NaCl}$ stress (Figure 3 and Supplementary Figure S4). Indeed, the finding that $D$. vulgaris cells were significantly more sensitive to $\mathrm{NaNO}_{3}$ than $\mathrm{NaCl}$ (Figure 1) indicates the involvement of inhibitory mechanisms in addition to the osmotic stress resulting from the elevated nitrate concentrations. Presumably, the more severe growth inhibition under nitrate stress (Figure 1a) could be attributed to the presence of the nitrate ions, as compared with chloride ions.

In contrast to $\mathrm{Cl}^{-}$, in some bacteria, the nitrate ion is redox active and can serve as a terminal electron acceptor in energy metabolism or as a source of nitrogen for biosynthesis, both requiring the reduction of nitrate coupled with electron transfer. However, nitrate-dependent growth of $D$. vulgaris has not been observed, which is consistent with the absence of nitrate reductase genes in the sequenced genome of $D$. vulgaris (Moura et al., 1997; Haveman et al., 2004; Heidelberg et al., 2004). Thus, it is unlikely that copious amounts of nitrogenous intermediates would be generated as toxic intermediates from nitrate reduction in $D$. vulgaris. It is suggested, however, that small amounts of nitrite, and subsequently other reactive nitrogen species, could be produced from non-specific reduction of nitrate by low potential reductases in $D$. vulgaris cells, such as the multiheme $c$-type cytochromes (Wall et al., 2007). Owing to the specificity of nitrite toxicity to sulfate reduction (Greene et al., 2003; Haveman et al., 2004), nitrite derived from nitrate could represent a major stress condition for $D$. vulgaris. It appears that the significant up-regulation of the hybrid cluster protein genes (DVU2543-2544) upon nitrate exposure (Table 1), which resembled a similar response pattern specific to nitrite stress (Greene et al., 2003; Haveman et al., 2004; He et al., 2006), would support the suggestion that nitrite stress is a result of nitrate exposure.

The initiation of nitrite stress responses upon exposure to nitrate in $D$. vulgaris could be of particular ecological significance in the persistence of SRB in environments with elevated levels of nitrate, which has been shown to effectively inhibit SRB populations in the environment (Jenneman et al., 1986; Davidova et al., 2001). More importantly, the nitrate inhibition of SRB is shown to be caused by nitrite, a key intermediate during microbial nitrate reduction (Greene et al., 2003; Voordouw et al., 2009). Thus, given the known toxicity of nitrite to SRB (Haveman et al., 2004; He et al., 2006), a potential impact of nitrate stress on SRB in the natural environment could be the subsequent occurrence of nitrite stress with the onset of microbial nitrate reduction. Even though nitrate cannot serve as an electron acceptor for D. vulgaris, nitrate is a common electron acceptor readily used by many other microorganisms. As a result, the presence of nitrate in the environment would rapidly result in the production of nitrite by microbial nitrate reduction. The initiation of stress responses for nitrite detoxification upon nitrate exposure would therefore, prepare the SRB population for the imminent inhibitory effects of nitrite produced from nitrate reduction and provide a physiological advantage to the survival of SRB in the environment.

Aside from components of salt stress and nitrite stress, involvement of oxidative stress response was also implicated during nitrate stress in $D$. vulgaris, with the up-regulation of the genes in the PerR regulon (Table 2), which is known to be responsive to oxidative stress (Rodionov et al., 2004). However, examination of the responses of $D$. vulgaris to other stress conditions reveals that the up-regulation of the Per-R regulon takes place not only under oxygen stress (Mukhopadhyay et al., 2007) but also under nitrite (He et al., 2006), salt (Mukhopadhyay et al., 2006) and heat (Chhabra et al., 2006) stress, suggesting that the response of the PerR regulon may not be specifically linked to nitrate. The same non-specific response could also be suggested for several other genes responsive to nitrate stress. For example, the gene for the phage shock protein A (DVU2988) was up-regulated in nitrate stress (Supplementary Table S1). However, this gene was also up-regulated under conditions of salt (Mukhopadhyay et al., 2006), heat (Chhabra et al., 2006) and oxygen (Mukhopadhyay et al., 2007) stress, suggesting that this response was not directly related to nitrate stress, rather a form of general stress response. 


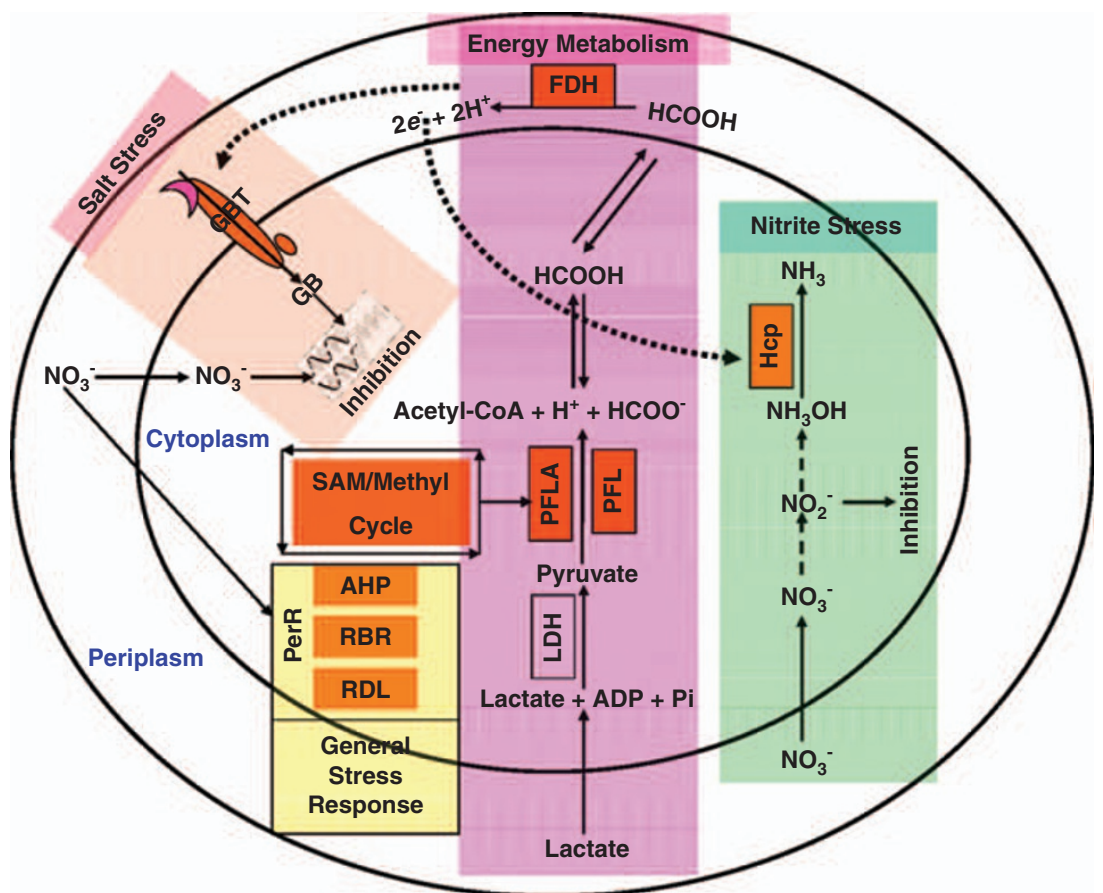

Figure 4 Conceptual model of responses to nitrate stress by $D$. vulgaris with linkages to both salt and nitrite stress in addition to shifts in energy metabolism. Colored symbols designate up-regulation. GBT: glycine/betaine ABC transporter; Hcp: hybrid cluster protein; PFL: pyruvate formate-lyase; PFLA: pyruvate formate-lyase activating enzyme; FDH: formate dehydrogenase; LDH: lactate dehydrogenase; AHP: alkyl hydroperoxide reductase; RBR: Rubrerythrin; RDL: Rubredoxin-like protein; SAM/Methyl cycle: $S$-adenosyl methionine cycle (details described in Supplementary Figure S2).

In contrast, the energetic consequences of nitrate stress could be considered as potential mechanisms contributing to the inhibition of $D$. vulgaris by nitrate. Indeed, our results indicate that a number of genes with functions in energy metabolism were among those that were highly up-regulated under nitrate stress, such as an operon consisting of genes related to the catabolism of pyruvate as a key metabolic intermediate, a pyruvate formatelyase (DVU2824) and its activating enzyme (DVU2825), as well as another operon encoding a formate dehydrogenase (DVU0586-0588) (Table 1). These regulatory events implicate a shift in energy metabolism to the increased flow of reducing equivalents through formate as a metabolic intermediate during nitrate stress. Notably, the activation of the pyruvate formate-lyase (DVU2824), a key enzyme in the generation of formate from the central metabolite pyruvate, has been shown to require the methyldonor SAM in other bacteria (Chase and Rabinowitz, 1968; Knappe and Schmitt, 1976). The increased flow of reducing equivalent during nitrate exposure could potentially be used by $D$. vulgaris as a mechanism to meet the demand for an increased electron flow by redox processes, such as the detoxification of nitrite ( $\mathrm{He}$ et al., 2006) generated from the reduction of nitrate by other microbial populations, thus providing a physiological advantage to the survival of these microorganisms in natural environments with high nitrate levels. Interestingly, genes involved in methyl/SAM metabolism were among those that were the most responsive to nitrate stress in D. vulgaris (Supplementary Table S1), thus linking the methyl/SAM metabolic pathway to the shift in energy metabolism (Supplementary Figure S2). However, a definitive relationship between the shift in energy metabolism and nitrate inhibition could not be established, given the limited scope of this study. Future work should be focused on elucidation of the roles of energy metabolism in nitrate stress.

Therefore, the response to nitrate stress by $D$. vulgaris was shown to be linked to the components of both osmotic and nitrite stress responses (Figure 4), which is illustrated by the up-regulation of the glycine/betaine transporter genes known to relieve salt stress (Mukhopadhyay et al., 2006) and the hybrid cluster protein gene identified specifically in nitrite stress (He et al., 2006). Nitrate stress also had an impact on energy metabolism by way of increased expression of the SAM/methyl cycle, along with the up-regulation of the pyruvate formate-lyase, resulting in a shift to the increased flow of reducing equivalents through formate as a metabolic intermediate. The increased flux of formate is likely processed by the periplasmic formate dehydrogenase, which was expressed at a higher level during nitrate stress. The involvement of the oxidative stress response pathway, however, might be the result of a more general stress response. Given the low similarities between the response profiles to nitrate and other stresses, less defined 
stress response pathways could also be important in nitrate stress, which might involve the shift in energy metabolism.

\section{Acknowledgements}

This work was a part of the Environmental Stress Pathway Project (ESPP) of the Virtual Institute for Microbial Stress and Survival (http://vimss.lbl.gov) supported by the US Department of Energy, Office of Science, Office of Biological and Environmental Research, Genomics: GTL Program, through contract DE-AC02-05CH11231 with the Lawrence Berkeley National Laboratory.

\section{References}

Abdelouas A, Lu YM, Lutze W, Nuttall HE. (1998). Reduction of U(VI) by indigenous bacteria in contaminated ground water. J Contam Hydrol 35: 217-233.

Bagwell CE, Liu X, Wu L, Zhou J. (2006). Effects of legacy nuclear waste on the compositional diversity and distributions of sulfate-reducing bacteria in a terrestrial subsurface aquifer. FEMS Microbiol Ecol 55: 424-431.

Bender KS, Yen H-CB, Hemme CL, Yang Z, He Z, He Q et al. (2007). Analysis of a ferric uptake regulator (Fur) mutant of Desulfovibrio vulgaris Hildenborough. Appl Environ Microbiol 73: 5389-5400.

Borglin S, Joyner D, Jacobsen J, Mukhopadhyay A, Hazen TC. (2009). Overcoming the anaerobic hurdle in phenotypic microarrays: generation and visualization of growth curve data for Desulfovibrio vulgaris Hildenborough. J Microbiol Methods 76: 159-168.

Brooks SC. (2001). Waste Characteristics of the Former S-3 Ponds and Outline of Uranium Chemistry Relevant to NABIR Field Research Center studies ORNL/TM-2001/27. NABIR Field Research Center: Oak Ridge, TN.

Butler JE, He Q, Nevin KP, He Z, Zhou J, Lovley DR. (2007). Genomic and microarray analysis of aromatics degradation in Geobacter metallireducens and comparison to a Geobacter isolate from a contaminated field site. BMC Genomics 8: 180.

Cayley S, Record Jr MT. (2003). Roles of cytoplasmic osmolytes, water, and crowding in the response of Escherichia coli to osmotic stress: biophysical basis of osmoprotection by glycine betaine. Biochemistry 42: 12596-12609.

Chang Y-J, Peacock AD, Long PE, Stephen JR, McKinley JP, MacNaughton SJ et al. (2001). Diversity and characterization of sulfate-reducing bacteria in groundwater at a uranium mill tailings site. Appl Environ Microbiol 67: 3149-3160.

Chardin B, Dolla A, Chaspoul F, Fardeau ML, Gallice P, Bruschi M. (2002). Bioremediation of chromate: thermodynamic analysis of the effects of $\mathrm{Cr}(\mathrm{VI})$ on sulfate-reducing bacteria. Appl Environ Microbiol 60: 352-360.

Chase T, Rabinowitz JC. (1968). Role of pyruvate and $S$-adenosylmethionine in activating the pyruvate formate-lyase of Escherichia coli. J Bacteriol 96: 1065-1078.

Chhabra SR, He Q, Huang KH, Gaucher SP, Alm EJ, He Z et al. (2006). Global analysis of heat shock response in Desulfovibrio vulgaris Hildenborough. J Bacteriol 188: 1817-1828.
Clark ME, He Q, He Z, Huang KH, Alm EJ, Wan X-F et al. (2006). Temporal transcriptomic analysis as Desulfovibrio vulgaris Hildenborough transitions into stationary phase during electron donor depletion. Appl Environ Microbiol 72: 5578-5588.

Davidova I, Hicks MS, Fedorak PM, Suflita JM. (2001). The influence of nitrate on microbial processes in oil industry production waters. J Ind Microbiol Biotechnol 27: 80-86.

Fields MW, Bagwell CE, Carroll SL, Yan T, Liu X, Watson DB et al. (2006). Phylogenetic and functional biomakers as indicators of bacterial community responses to mixed-waste contamination. Environ Sci Technol 40: 2601-2607.

Finneran KT, Housewright ME, Lovley DR. (2002). Multiple influences of nitrate on uranium solubility during bioremediation of uranium-contaminated subsurface sediments. Environ Microbiol 4: 510-516.

Gillan DC, Danis B, Pernet P, Joly G, Dubois P. (2005). Structure of sediment-associated microbial communities along a heavy metal contaminated gradient in the marine environment. Appl Environ Microbiol 71: 679-690.

Greene EA, Hubert C, Nemati M, Jenneman GE, Voordouw G. (2003). Nitrite reductase activity of sulfate-reducing bacteria prevents their inhibition by nitrate-reducing, sulfide-oxidizing bacteria. Environ Microbiol 5: 607-617.

Gu B, Wu W-M, Ginder-Vogel MA, Yan H, Fields MW, Zhou J et al. (2005). Bioreduction of uranium in a contaminated soil column. Environ Sci Technol 39: 4841-4847.

Haveman SA, Greene EA, Stilwell CP, Voordouw JK, Voordouw G. (2004). Physiological and gene expression analysis of inhibition of Desulfovibrio vulgaris Hildenborough by nitrite. J Bacteriol 186: 7944-7950.

Haveman SA, Greene EA, Voordouw G. (2005). Gene expression analysis of the mechanism of inhibition of Desulfovibrio vulgaris Hildenborough by nitratereducing, sulfide-oxidizing bacteria. Environ Microbiol 7: 1461-1465.

Hazen TC, Stahl DA. (2006). Using the stress response to monitor process control: pathways to more effective bioremediation. Curr Opin Biotechnol 17: 285-290.

He Q, Huang KH, He Z, Alm EJ, Fields MW, Hazen TC et al. (2006). Energetic consequences of nitrite stress in Desulfovibrio vulgaris Hildenborough, inferred from global transcriptional analysis. Appl Environ Microbiol 72: 4370-4381.

Heidelberg JF, Seshadri R, Haveman SA, Hemme CL, Paulsen IT, Kolonay JF et al. (2004). The genome sequence of the anaerobic, sulfate-reducing bacterium Desulfovibrio vulgaris Hildenborough. Nat Biotechnol 22: 554-559.

Istok JD, Senko JM, Krumholz LR, Watson D, Bogle MA, Peacock A et al. (2004). In situ bioreduction of technetium and uranium in a nitrate-contaminated aquifer. Environ Sci Technol 38: 468-475.

Jain N, Thatte J, Braciale T, Ley K, O’Connell M, Lee JK. (2003). Local-pooled-error test for identifying differentially expressed genes with a small number of replicated microarrays. Bioinformatics 19: 1945-1951.

Jenneman GE, McInerney MJ, Knapp RM. (1986). Effect of nitrate on biogenic sulfide production. Appl Environ Microbiol 51: 1205-1211.

Joachimiak MP, Weissman JL, May BCH. (2006). JColorGrid: software for the visualization of biological measurements. BMC Bioinformatics 7: 225. 
Jones HE, Trudinger PA, Chambers LA, Pyliotis NA. (1976). Metal accumulation by bacteria with particular reference to dissimilatory sulfate-reducing bacteria. Z Allg Microbiol 16: 425-435.

Knappe J, Schmitt T. (1976). A novel reaction of $S$-adenosyl-L-methionine correlated with the activation of pyruvate formate-lyase. Biochem Biophys Res Commun 71: 1110-1117.

Landa ER. (2005). Microbial biogeochemistry of uranium mill tailings. Adv Appl Microbiol 57: 113-130.

Liu H, Sadygov RG, Yates III JR. (2004). A model for random sampling and estimation of relative protein abundance in shotgun proteomics. Anal Chem 76: 4193-4201.

Lloyd JR, Renshaw JC. (2005). Bioremediation of radioactive waste: radionuclide-microbe interactions in laboratory and field-scale studies. Curr Opin Biotechnol 16: $254-260$.

Lloyd JR, Ridley J, Khizniak T, Lyalikova NN, Macaskie LE. (1999). Reduction of technetium by Desulfovibrio desulfuricans: biocatalyst characterization and use in a flowthrough bioreactor. Appl Environ Microbiol 65: 2691-2696.

Lovley DR, Phillips EJP. (1992). Reduction of uranium by Desulfovibrio desulfuricans. Appl Environ Microbiol 58: 850-856.

Lovley DR, Roden EE, Phillips EJP, Woodward JC. (1993a). Enzymatic iron and uranium reduction by sulfatereducing bacteria. Marine Geol 113: 41-53.

Lovley DR, Widman PK, Woodward JC, Phillips EJP. (1993b). Reduction of uranium by cytochrome $C_{3}$ of Desulfovibrio vulgaris. Appl Environ Microbiol 59: 3572-3576.

Moura I, Bursakov S, Costa C, Moura JJG. (1997). Nitrate and nitrite utilization in sulfate-reducing bacteria. Anaerobe 3: 279-290.

Mukhopadhyay A, He Z, Alm EJ, Arkin AP, Baidoo EE, Borglin SC et al. (2006). Salt stress in Desulfovibrio vulgaris Hildenborough: an integrated genomics approach. J Bacteriol 188: 4068-4078.

Mukhopadhyay A, Redding AM, Joachimiak MP, Arkin AP, Borglin SE, Dehal PS et al. (2007). Cell-wide responses to low-oxygen exposure in Desulfovibrio vulgatis Hildenborough. J Bacteriol 189: 5996-6010.

NABIR. (2003). Bioremediation of metals and radionuclides: what it is and how it works. In: Hazen TC, Benson SM, Metting FB, Faison B, Palmisano AC, McCullough J (eds). NABIR Primer. 2nd edn. Lawrence Berkeley National Laboratory: Berkeley, CA. pp 1-78.

Nyman JL, Marsh TL, Ginder-Vogel MA, Gentile M, Fendorf S, Criddle C. (2006). Heterogeneous response to biostimulation for $\mathrm{U}(\mathrm{VI})$ reduction in replicated sediment microcosms. Biodegradation 17: 303-316.

Payne RB, Gentry DA, Rapp-Giles BJ, Casalot L, Wall JD. (2002). Uranium reduction by Desulfovibrio desulfuricans strain G20 and a cytochrome $C_{3}$ mutant Appl Environ Microbiol 68: 3129-3132.

Pereira PM, He Q, Valente FMA, Xavier AV, Zhou J, Pereira IAC et al. (2008). Energy metabolism in Desulfovibrio vulgaris Hildenborough: insights from transcriptome analysis. Antonie van Leeuwenhoek 93: 347-362.

Riley RG, Zachara JM. (1992). Chemical Contaminants on DOE Lands and Selection of Contaminant Mixtures for Subsurface Science Research DOE/ER-0547T. US Department of Energy: Washington, DC.

Rodionov DA, Dubchak I, Arkin AP, Alm E, Gelfand MS. (2004). Reconstruction of regulatory and metabolic pathways in metal-reducing $\delta$-Proteobacteria. Genome Biol 5: R90.

Stolyar S, He Q, Joachimiak MP, He ZL, Yang ZK, Borglin SE et al. (2007). Response of Desulfovibrio vulgaris to alkaline stress. J Bacteriol 189: 8944-8952.

Valls M, de Lorenzo V. (2002). Exploiting the genetic and biochemical capacities of bacteria for the remediation of heavy metal pollution. FEMS Microbiol Rev 26: 327-338.

van den Berg WAM, Hagen WR, van Dongen WMAM. (2000). The hybrid-cluster protein ('prismane protein') from Escherichia coli: characterization of the hybridcluster protein, redox properties of the $[2 \mathrm{Fe}-2 \mathrm{~S}]$ and [4Fe-2S-2O] clusters and identification of an associated NADH oxidoreductase containing FAD and [2Fe-2S]. Eur J Biochem 267: 666-676.

Voordouw G, Grigoryan AA, Lambo A, Lin SP, Park HS, Jack TR et al. (2009). Sulfide remediation by pulsed injection of nitrate into a low temperature Canadian heavy oil reservoir. Environ Sci Technol 43: 9512-9518.

Wall JD, Krumholz LR. (2006). Uranium reduction. Annu Rev Microbiol 60: 149-166.

Wall JD, Yen H-CB, Drury EC. (2007). Evaluation of stress response in sulphate-reducing bacteria through genome analysis. In: Barton LL, Hamilton WA (eds). Sulphate-Reducing Bacteria: Environmental and Engineered Systems. Cambridge University Press: Cambridge, UK. pp 141-165.

Wang SC, Frey PA. (2007). S-adenosylmethionine as an oxidant: the radical SAM superfamily. Trends Biochem Sci 32: 101-110.

Wei J, Sun J, Yu W, Jones A, Oeller P, Keller M et al. (2005). Global proteome discovery using an online threedimensional LC-MS/MS. I Proteome Res 4: 801-808.

Wolfe MT, Heo J, Garavelli JS, Ludden PW. (2002). Hydroxylamine reductase activity of the hybrid cluster protein from Escherichia coli. J Bacteriol 184: 5898-5902.

Wolters DA, Washburn MP, Yates III JRY. (2001). An automated multidimensional protein identification technology for shotgun proteomics. Anal Chem 73: 5683-5690.

Supplementary Information accompanies the paper on The ISME Journal website (http://www.nature.com/ismej) 